\title{
IDENTIFICATION OF SIGNIFICANT RISK FACTORS OF GUARANTEED MAXIMUM PRICE (GMP) CONTRACTS
}

\author{
A.D. Palihakkara ${ }^{1}$ and B.A.K.S. Perera ${ }^{2}$
}

\begin{abstract}
The construction industry is a risk-prone industry where projects are implemented in a dynamic environment with frequent exposure to various uncertainties. A construction contract is a document that allocates the risks associated with a construction project among the project stakeholders. Guaranteed Maximum Price (GMP) contracts have become popular as a project delivery method because they provide the client with a high degree of cost certainty through a fixed price cap that the contractor cannot exceed. However, most of the GMP projects are risky. Thus, the significant risk factors of GMP projects have to be identified to ensure their successful completion. This study, therefore, aimed to identify and rank the most significant risk factors present in GMP contracts. The study adopted a quantitative approach, which included a Delphi survey conducted in two rounds and a statistical analysis of the survey data. The most significant risk factors associated with GMP contracts were ranked according to their impact on the projects and their probability of occurrence (severity). Poorly defined scope of work and design changes were found to be the most significant risk factors associated with GMP contracts. The other significant risk factors of the projects are related to the scope of work, design, documentation, unfamiliarity with the GMP concept, agreed GMP value, and financial failures of the client and contractor.
\end{abstract}

Keywords: Guaranteed Maximum Price (GMP) contracts; Risk ranking; Significant risks.

\section{INTRODUCTION}

The construction industry is a risk-prone industry, with the projects inheriting risks and uncertainties from their initiation to completion (Chilumo et al., 2020). The form of payment or type of contract used in a project has a significant impact on the risk allocation of the project (Osipova and Eriksson, 2011). Construction contracts are mainly of two types: fixed-price contracts and cost-reimbursement contracts (Eriksson et al., 2017). A Guaranteed Maximum Price (GMP) contract is a hybrid arrangement of fixed-price and cost-reimbursement contracts (Boukendour and Bah, 2001).

Unlike conventional project delivery methods, the GMP mechanism has a high level of risks as the GMP level is decided before the completion of the design (Chan et al., 2010a). Wong (2006) stated that GMP contracts are a viable option for sophisticated and capitalintensive construction projects with high technical and financial risks. Although GMP contracts have been adopted for a considerable time, not every project has been successful

\footnotetext{
${ }^{1}$ Department of Building Economics, University of Moratuwa, Sri Lanka, asha.dulanjalie@ gmail.com

${ }^{2}$ Department of Building Economics, University of Moratuwa, Sri Lanka, kanchana@uom.lk
} 
(Joseph, 2011). According to Rojas and Kell (2008), in the United States, nearly $75 \%$ of school projects and $80 \%$ of non-school projects procured using the GMP mechanism have exceeded their GMP values, thereby failing to reap the main benefit of the GMP mechanism. Several studies have been conducted on the various aspects of GMP contracts. Most of these studies have focussed on both GMP contracts and Target Cost Contracts (TCCs). However, literature on the significant risk factors associated with GMP contracts in terms of their impact on the project and probability of occurrence is scarce. Zimina et al. (2012) state GMP contracts are a form of TCCs in which the risks are shifted towards the contractor. Thus, the risk behaviour in GMP contracts is more complicated than in TCCs. Henceforth, this study aims at identifying and ranking risk factors specifically for GMP contracts.

\section{LITERATURE REVIEW}

\subsection{GMP CONTRACTS}

In a GMP contract, the contractor agrees to complete the project at a cost not exceeding a pre-agreed limit; thus, any cost overrun has to be borne by the contractor (Chan et al., 2010a). The price ceiling under which the contractor has to deliver the agreed scope of work is called the Guaranteed Maximum Price (Anvuur and Kumaraswamy, 2010). If the work is completed below the GMP, the difference between the actual cost and the GMP has to be shared between the client and contractor according to a pre-agreed formula.

\subsection{RISK FACTORS ASSOCIATED WITH GMP CONTRACTS}

GMP contracts have been in place for a considerable period; nonetheless, project failures are still possible even with GMP contracts because of the high risks (Chan et al., 2012). Therefore, risk factors of GMP contracts have to be identified. Table 1 illustrates the risk factors identified by past researchers.

Table 1: Risk factors of GMP contracts

\begin{tabular}{|c|c|c|c|c|c|c|c|c|c|c|c|c|}
\hline \multirow{2}{*}{ Risk Factor } & \multicolumn{12}{|c|}{ Researchers } \\
\hline & A $\mathbf{B}$ & C I & $\mathbf{E}$ & $\mathbf{F}$ & $\mathbf{G}$ & H I & I J & & $\mathbf{K} \mathbf{L}$ & M I & $\mathbf{N O}$ & $\mathbf{O P}$ \\
\hline Change in the scope of work & $\checkmark$ & $\checkmark$ & & $\checkmark$ & $\checkmark$ & $\checkmark$ & & & $\checkmark$ & $\checkmark$ & $\checkmark$ & $\checkmark$ \\
\hline Exchange rate variation & $\checkmark \checkmark$ & & & & & & $\checkmark$ & & $\checkmark$ & & & \\
\hline Scope creep & $\checkmark$ & & & & & & & & & & $\checkmark$ & \\
\hline $\begin{array}{l}\text { Incompleteness of the design at the time of } \\
\text { inviting tenders }\end{array}$ & $\checkmark$ & & & & & & & & $\checkmark$ & & $\checkmark$ & $\checkmark$ \\
\hline Poorly defined scope of work & $\checkmark$ & & & & $\checkmark$ & & & & $\checkmark$ & & $\checkmark$ & \\
\hline Acts of God & & $\checkmark$ & 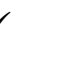 & $\checkmark$ & & & $\checkmark \checkmark$ & & $\checkmark$ & & & $\checkmark$ \\
\hline Inadequacy of the design & & & & & & & $\checkmark$ & & & & & \\
\hline Buildability issues & & & & $\checkmark$ & & & $\checkmark$ & & $\checkmark$ & & & $\checkmark$ \\
\hline Changes in government regulations & & $\checkmark$ &  & $\checkmark$ & & & $\checkmark \checkmark$ & & $\checkmark$ & & & $\checkmark$ \\
\hline Inconsistencies in documents & & & & $\checkmark$ & & & & & & & & \\
\hline Delayed payments & & $\checkmark$ & 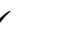 & $\checkmark$ & & & & & $\checkmark$ & & & $\checkmark$ \\
\hline Design changes & & & & $\checkmark$ & & $\checkmark$ & & & & & & \\
\hline
\end{tabular}




\section{Researchers}

$\begin{array}{llllllllllllllllll}\text { A } & \text { B } & \text { C } & \text { D } & \text { E } & \text { F } & \text { G } & \text { H } & \text { I } & \text { J } & \text { K } & \text { L } & \text { M } & \mathbf{N} & \mathbf{O} & \mathbf{P}\end{array}$

Variations

Defective designs

Unforeseeable design development risks encountered during the tendering stage

Overpayment by the client because the risks have been inflated by the contractor

Errors and omissions in the tender document

Delay in obtaining labour, material, and equipment

Delay in solving contractual issues

Inexperienced bidders

Difficulties in valuing revised contract prices

Financial failures of the client

Financial failures of the contractor

Inclement weather

Inexperienced contractors

Inflation

Failure to use a standard form of contract

Possibility of compromising project quality

Subcontractor failures

Third-party delays

Uneven cost sharing ratios

Unforeseen ground conditions

Improper selection of the project team

Unrealistic maximum price agreed in the contract

Quantities of work done exceeding the estimated quantities

Unfamiliarity with the GMP concept



A - Chan et al. (2011), B - Al-Ajmi and Makinde (2018), C - Olawale and Sun (2010), D - Ahmed et al. (1999), E - Broome and Perry (2002), F - Rahman and Kumaraswamy (2005), G - Fan and Greenwood (2004), H - Oztas and Okmen (2004), I - Environment Transport and Works Bureau (2005), J - Bing et al. (2005), K - Joseph (2011), L - Badenfelt (2008), M - Chan et al. (2014), N - Chan et al. (2010a), O - Rotimi et al. (2009), P - Chan et al. (2012)

As Table 1 shows, GMP contracts have many risk factors. According to Chan et al. (2010a), contractual risk factors in GMP contracts depend on four main factors: nature of the variations, quality and clarity of the tender documents, changes made to the project scope, and appropriateness of the GMP value. The authors stated that errors, omissions, and discrepancies in the contract and tender documents might contribute to conflicts and disputes between contracting parties. Most GMP contracts are concluded at a time when 
the designs have been completed only partially. Thus, important cost centres of the project scope may not be known at the time of inviting tenders, making it difficult to arrive at a realistic GMP value (Rotimi et al., 2009) and leading to variations in the post-contract stage (Chan et al., 2011). Furthermore, Davis Langdon and Seah Singapore (2004) stated deciding the GMP value with an incomplete design is risky for both the client and contractor. Olawale and Sun (2010) added that project scope changes would cause cost and time implications and that if not managed well, they would have a negative impact on the project cost and schedules.

When following the GMP approach, the client must ensure that qualified and wellexperienced bidders are selected to bid. Otherwise, the project can be risky (Al-Ajmi and Makinde, 2018). Because GMP contracts are incentive-based contracts, inflation and exchange rate variations have a significant impact on the projects. According to Chan et al. (2010a), the fluctuation of material prices and varying market trends pertaining to building design are significant economic risk factors. All these risk factors will ultimately cause cost and time implications (Olawale and Sun, 2010). Because a large number of risk factors are associated with GMP contracts, the identification of the most significant factors among them is important for the successful completion of the projects.

\subsection{IMPORTANCE OF IDENTIFYING THE SIGNIFICANT RISK FACTORS ASSOCIATED WITH GMP CONTRACTS}

GMP contracting is a novel procurement strategy used by construction practitioners. GMP contracts are used in large-scale investments in which the client's risk has been lowered and the contractor's risk is inflated. Compared with conventional project delivery methods, the GMP mechanism has a high level of risk as the GMP level is decided before the completion of the design (Chan et al., 2010a). Although GMP contracts have been used in practice for a considerable time, not every GMP project has become successful (Joseph C. H., 2011). The risk factors of GMP contracts have been identified to some extent by past studies. Nevertheless, most of these past studies have focused on GMP contracts and TCCs collectively. However, unlike TCCs, GMP contracts have only a gain-sharing mechanism. Therefore, the risk the contractor has to face in GMP contracts is high. Hence, conducting a separate risk identification and analysis in respect of GMP contracts will be appropriate due to the significant differences between TCCs and GMP contracts.

\section{METHODOLOGY}

Delphi technique is a data collection and analysing technique that employs multiple iterations to enable a selected set of respondents to reach a consensus on a subject through a series of questionnaire surveys (Hsu and Sandford, 2007). It was appropriate for this study because those who participated in the questionnaire surveys were experienced professionals capable of providing informed opinions (Nworie, 2011), who could quantify the risk factors and their impacts on the project (Hallowell and Gambatese, 2010). The data collection was conducted in two rounds of questionnaire surveys, a surveying research strategy was adopted as a part of the quantitative approach used. A quantitative approach enables the identification of statistical relationships among variables (Basias and Pollalis, 2018). Thus, the quantitative approach used in the study enabled the survey respondents to rank the most significant risk factors of GMP contracts statistically. 


\section{Delphi Round 1: Identification of the Significant Risk Factors of GMP Contracts}

$$
R I I=\frac{\sum W_{n}}{N \times A}
$$

Where RII = Relative Importance Index, $\mathrm{W}=$ Rating of each factor given by a respondent, $\mathrm{n}=$ Frequency of response, $\mathrm{N}=$ Total number of responses, and $\mathrm{A}=$ Highest weight.

According to Rooshdi et al. (2018), responses on a scale of 1 to 5 give RII values between 0 and 1 . Factors with RII values between 1 to 0.8 are highly significant. Hence, through the first Delphi round, risk factors that had their RII exceeding 0.8 were identified.

Delphi Round 2: Identification of the Severity of the Significant Risk Factors of GMP Contracts using their Impact on the Project and Probability of Occurrence

$$
\begin{gathered}
S_{j}^{i}=\propto_{j}^{i} \beta_{j}^{i} \\
R S^{i}=\frac{\sum_{j=1}^{n} S_{j}^{i}}{n}
\end{gathered}
$$

In Equations 02 and 03, $\mathrm{n}=$ number of responses, $S_{j}^{i}=$ Evaluation of risk severity of the $\mathrm{i}^{\text {th }}$ risk factor by the $\mathrm{j}^{\text {th }}$ respondent, $\propto_{j}^{i}=$ Evaluation of the frequency level of risk occurrence by the $\mathrm{j}^{\text {th }}$ respondent, $\beta_{j}^{i}=$ Evaluation of the significance of risk occurrence by the $\mathrm{j}^{\text {th }}$ respondent, and $R S^{i}=$ Risk Severity Index of the $\mathrm{i}^{\text {th }}$ risk factor.

\section{RESEARCH FINDINGS}

\subsection{DELPHI ROUND 1}

During the first Delphi round, the respondents were asked to rate the significance of the identified risk factors of GMP contracts on a five-point Likert scale. Table 2 lists the risk factors that had an RII value exceeding 0.800 (highly significant risk factors). A Cronbach's alpha of 0.879 , which exceeds the threshold value of 0.700 , indicates that the

\begin{tabular}{|c|c|c|c|}
\hline No. & Risk Factor & RII & SD \\
\hline 1 & Poorly defined scope of work & 0.900 & 0.726 \\
\hline 2 & Design changes & 0.889 & 0.724 \\
\hline 3 & Changes in the scope of work & 0.884 & 0.948 \\
\hline 4 & Unrealistic maximum price agreed in the contract & 0.879 & 0.823 \\
\hline 5 & Defective design & 0.874 & 0.819 \\
\hline 6 & Failure to complete the design before tenders are invited & 0.862 & 0.928 \\
\hline 7 & Financial failures of the contractor & 0.859 & 0.996 \\
\hline 8 & Errors and omissions in the tender document & 0.855 & 0.820 \\
\hline 9 & $\begin{array}{l}\text { Actual quantities of the work executed exceeding their estimated } \\
\text { quantities }\end{array}$ & 0.853 & 1.032 \\
\hline 10 & Failure to use a standard form of contract & 0.850 & 0.937 \\
\hline 11 & Unfamiliarity with the GMP concept & 0.849 & 0.895 \\
\hline 12 & Financial failures of the client & 0.838 & 1.079 \\
\hline
\end{tabular}
inputs have high reliability and consistency (Aghimien et al., 2020).

Table 2: Significant risk factors of GMP contracts 


\begin{tabular}{llcc}
\hline No. & \multicolumn{1}{c}{ Risk Factor } & RII & SD \\
\hline 13 & $\begin{array}{l}\text { Unforeseeable risks associated with design development during the } \\
\text { tendering stage }\end{array}$ & 0.832 & 1.103 \\
14 & Scope creep & 0.822 & 1.048 \\
15 & Inconsistencies in the documents & 0.821 & 1.008 \\
16 & Inexperience of the contractors & 0.816 & 1.024 \\
17 & Inadequacy of the design & 0.805 & 0.911 \\
\hline
\end{tabular}

Among the risk factors listed in Table 1, only 17 risk factors recorded RII values exceed 0.800 , which are highly significant. The most significant risk factors have RII values ranging from 0.900 to 0.805 . Among these most significant risk factors, seven are related to project scope or design. Risk factors such as 'Errors and omissions in the tender document', 'Failure to use a standard form of contract' and 'Inconsistencies in the documents' have higher RII values, suggesting that project scope and design and other relevant documents should be clear, precise, and well prepared; otherwise, the project may face a high level of risk. Financial failures of the client and the contractor are two prominent risk factors associated with GMP contracts. 'Unrealistic maximum price agreed in the contract' has the fourth highest RII value (0.879), indicating the importance of accurately calculating the GMP value. Thus, the whole concept of GMP contracts revolves around the GMP value, the most distinctive feature of GMP contracts.

\subsection{DELPHI ROUND 2}

\subsubsection{Overall Severity of Significant Risk Factors}

The second Delphi round was conducted to evaluate the significant risk factors of GMP contracts in relation to their impact on the project and probability of occurrence. The Severity Index (SI) of each risk factor was calculated based on its level of impact on the project and probability of occurrence. Table 3 illustrates the severity indices of the risk factors listed in their descending order of significance. The Cronbach's alpha of the data set in Table 3 was 0.857 , suggesting that the results have high reliability and internal consistency.

Table 3: Severity of the significant risk factors

\begin{tabular}{clcccc}
\hline Code & \multicolumn{1}{c}{ Risk Factor } & Impact & Probability & SI & Ranking \\
\hline R1 & Poorly defined scope of work & 4.536 & 3.714 & 16.847 & 1 \\
R2 & Design changes & 4.179 & 3.607 & 15.073 & 2 \\
R3 & Changes in the scope of work & 4.321 & 3.429 & 14.816 & 3 \\
R4 & Inadequacy of the design & 3.889 & 3.296 & 12.819 & 4 \\
R5 & $\begin{array}{l}\text { Errors and omissions in the tender } \\
\text { document }\end{array}$ & 3.929 & 3.250 & 12.768 & 5 \\
& Unforeseeable risks associated with & & & & \\
R6 & design development during the & 3.778 & 3.148 & 11.893 & 6 \\
& tendering stage & & & & \\
R7 & Scope creep & 3.963 & 3.000 & 11.889 & 6 \\
R8 & Unfamiliarity with the GMP concept & 3.654 & 3.154 & 11.524 & 8
\end{tabular}




\begin{tabular}{|c|c|c|c|c|c|}
\hline Code & Risk Factor & Impact & Probability & SI & Ranking \\
\hline R9 & $\begin{array}{l}\text { Actual quantities of the work executed } \\
\text { exceeding their estimated quantities }\end{array}$ & 3.857 & 2.964 & 11.434 & 9 \\
\hline $\mathrm{R} 10$ & Inexperienced contractors & 4.071 & 2.750 & 11.196 & 10 \\
\hline $\mathrm{R} 11$ & $\begin{array}{l}\text { Failure to complete the design before } \\
\text { tenders are invited }\end{array}$ & 3.964 & 2.821 & 11.185 & 11 \\
\hline $\mathrm{R} 12$ & Defective design & 4.038 & 2.731 & 11.028 & 12 \\
\hline $\mathrm{R} 13$ & Inconsistencies in the documents & 3.500 & 3.115 & 10.904 & 13 \\
\hline $\mathrm{R} 14$ & Financial failures of the contractor & 3.963 & 2.593 & 10.274 & 14 \\
\hline $\mathrm{R} 15$ & $\begin{array}{l}\text { Unrealistic maximum price agreed in } \\
\text { the contract }\end{array}$ & 4.143 & 2.429 & 10.061 & 15 \\
\hline $\mathrm{R} 16$ & Financial failures of the client & 4.222 & 2.370 & 10.008 & 16 \\
\hline $\mathrm{R} 17$ & $\begin{array}{l}\text { Failure to use a standard form of } \\
\text { contract }\end{array}$ & 3.370 & 2.815 & 9.487 & 17 \\
\hline
\end{tabular}

The scatter diagram provided in Figure 1 was plotted using the impact and probability values listed in Table 3.



Figure 1: Risk impact probability matrix

R1 and R2 risk factors are in the red zone of the Impact Probability Matrix (Figure 1), indicating that the severity of each of the two risk factors is at an extremely high level. The severity indices of 'Poorly designed scope of work' (R1) and 'Design changes' (R2) are 16.847 and 15.073, respectively. The other 15 risk factors show a high level of severity and, therefore, are in the orange zone of the Impact Probability Matrix. The severity indices of these 15 risk factors fall in the 14.816-9.487 range. Thus, all of these 15 risk factors have a high level of risk. According to the rankings shown in Table 3, the most significant risk factors are related to the scope of work and design of the project. 


\subsubsection{The Severity of the Significant Risk Factors based on their Impact on the Project and Probability of Occurrence}

As Table 3 shows, the impact and probability levels of the risk factors vary. None of the risk factors has a probability rating exceeding 4 . The highest probability rating of 3.714 was for 'Poorly defined scope of work.' By contrast, seven of the risk factors have impact ratings exceeding 4. Furthermore, even though the risk factors such as 'Failure to complete the design before tenders are invited,' 'Inexperienced contractors,' 'Defective design' and 'Unrealistic maximum price agreed in the contract' have high levels of impact on a project, their probability of occurrence is low and therefore have received low rankings. One respondent opined that when the design is incomplete, no experienced and knowledgeable contractor would agree to the GMP value without seeking clarifications about the scope of work. Hence, the probability of occurrence of each of these risk factors will be low, although their impacts will be high if they ever occur. Another respondent stated that generally, in GMP projects, comprehensive information about the design is not available at the time of inviting tenders, which makes the clients prefer GMP contracts to other types of contracts, such as lump sum contracts, which require the design to be substantially completed at the time of inviting tenders. Hence, the probability of occurrence of these risk factors is high, and when they occur, their impacts on the projects will be high. According to Table 3, the probability of occurrence of a risk factor has a significant influence on its severity. For example, 'Financial failures of the client' has the third-highest impact value, although it is ranked lower with regard to severity because of its low probability of occurrence. The impact of 'Unforeseeable risks associated with design development during the tendering stage' is low, although it has a high ranking with regard to severity because of its high probability of occurrence. 'Failure to use a standard form of contract' has received a low ranking because the rights and obligations of the parties are stated clearly in a GMP contract making low the impact of the risk of not having a standard form of contract.

\subsection{DISCUSSION}

The most critical risk factors identified in the study are 'Poorly defined scope of work' and 'Design changes'. Most of the significant risk factors that were identified are connected to the scope of work and design. Considering their impact on a project, Chan et al. (2010a) suggested that 'Scope creep' and 'Poorly defined scope of work' might lead to a considerable number of GMP variations, ultimately making the project duration increase and project cost escalate. Fan and Greenwood (2004) expressed that in order to achieve their objectives, the client and contractor will express different opinions about common issues; thus, a poorly defined scope of work would promote disputes between the two parties.

Some of the significant risk factors, such as 'Errors and omissions in the tender document', 'Inconsistencies in the documents', and 'Failure to use a standard form of contract', were associated with documentation errors. According to Chan et al. (2010a), the quality/clarity of tender documents is a key contractual risk associated with GMP contracts because the fundamental tool used to allocate risks is the tender document. Ma and Beh (2011) identified the unavailability of a standard form of contract for GMP contracts as a major difficulty when allocating risks and responsibilities among the project players. According to Joseph (2011), unfamiliarity with the GMP concept may cause 
difficulties in setting the GMP value, monitoring the changes in the GMP value as the work progresses, and determining the profit-sharing formula.

Most of the previous studies on the risk factors associated with GMP contracts were conducted collectively on both TCC and GMP contracts. Furthermore, the literature that identifies the significant risk factors of GMP contracts has not addressed the severity of the risk factors in terms of their impact on the projects and probability of occurrence. The survey respondents accepted all the risk factors identified through the literature review. The study findings suggest that all of these risk factors are significant to some extent in GMP projects. Many of the past researchers found that the scope and design of the project might have a significant impact on anticipated risks, as revealed by this study as well. Joseph (2011) ranked the risk factors associated with TCCs and GMP contracts implemented in Hong Kong, and the findings are almost similar to the findings of this study. Five of the significant risk factors identified by Joseph (2011) were identified as significant in this study too. Moreover, Chan et al. (2010a) ranked the perceived risk factors of TCCs/GMP contracts in Hong Kong and identified changes in the scope of work and quality and clarity of tender documents as the two most significant risk factors present in the contracts. Chan et al. (2010b) ranked the key risk factors of TCCs/GMP contracts, and the results are considerably similar to the results of this study. Risk factors such as 'Inexperienced contractors', 'Failure to use a standard form of contract', and 'Changes in the scope of work' have been identified as significant risk factors by both studies. Risk factors such as the financial failures of the client and contractor have not been addressed in the previous studies on the risk factors in GMP contracts and TCCs. However, Ahmed et al. (1999) and Rahman and Kumaraswamy (2005) have addressed the impact of these two risk factors on the overall project irrespective of the type of contract employed. Nevertheless, the findings of this study reveal that financial failures of the client and contractors have a significant effect on the completion of GMP projects. The impact and probability of occurrence of each risk factor identified in this study may vary with project conditions and nature.

\section{CONCLUSIONS AND RECOMMENDATIONS}

The aim of the study was achieved through a cumulative process consisting of a literature review and a two-round Delphi survey. Among the 44 risk factors identified through the literature review, 17 are of high significance, with their RII values exceeding 0.800 . During the second round, all of these 17 risk factors were ranked based on their severity indices. Two of the risk factors, namely 'Poorly defined scope of work' and 'Design changes' obtained an extremely high severity level. The rest of the 15 risk factors had only a high severity level. The majority of the risk factors of high or extreme severity are related to project scope, design, and documentation. Furthermore, 'Poorly defined scope of work', 'Design changes', 'Changes in the scope of work', 'Inexperienced contractors', 'Defective design', 'Unrealistic maximum price agreed in the contract' and 'Financial failures of the client' have a high impact on the GMP process.

GMP contracts are suitable for projects that need early contractor involvement. It is strongly recommended that a clear and explicit definition of the scope of work be provided during the tendering stage. The project team should ensure that the design has been developed to a level that GMP contracts can handle and that bidders can quote their prices accurately. As the contractor's risk is inflated in the GMP approach, the contractor needs to price the tender to correspond to the risks associated with the project. Moreover, 
issues due to changes made in the scope of work cause disputes between the parties to the contract; hence, the client and the contractor will have to agree on the types of events, such as the changes made to design development during the tendering stage, that will make it necessary to recalculate the GMP value. It is also important to decide early during project planning the stage at which the contractor has to get involved during design development and how the responsibilities pertaining to the design and engineering-related work are shared between the contractor and the client.

The primary outcome of this study is the identification of the most significant risk factors of GMP contracts. Thus, the study findings can be used as a reference when conducting further studies on the different aspects of GMP contracts. Moreover, the findings would help the successful implementation of worldwide GMP projects and overcome the challenges of adopting a novel contracting strategy like GMP contracts. Furthermore, the findings of the study were limited to the overall perspective of the client, contractor, and consultant, and the risks were ranked without considering a specific procurement type.

\section{REFERENCES}

Aghimien, D.O., Aigbavboa, C.O. and Oke, A.E., 2020. Critical success factors for digital partnering of construction organisations - A Delphi study. Engineering, Construction and Architectural Management, 27(10), pp. 3171-3188.

Ahmed, S.M., Ahmad, R. and Saram, D.D., 1999. Risk management trends in the Hong Kong construction industry: A comparison of contractors and owners' perceptions. Engineering, Construction and Architectural Management, 6(3), pp. 225-234.

Al-Ajmi, H.F. and Makinde, E., 2018. Risk management in construction projects. Journal of Advanced Management Science, 6(2), pp. 113-116.

Anvuur, A.M. and Kumaraswamy, M.M., 2010. Promises, pitfalls and shortfalls of the guaranteed maximum price (GMP) approach: Comparative case study. In: Egbu, C. (ed). $26^{\text {th }}$ Annual ARCOM Conference, Leeds, UK, 6-8 September 2010, Association of Researchers in Construction Management, pp. 1079-1088.

Silver, K., 1991. Electronic Mail: The New Way to Communicate. In: Raitt, D.I. (ed). $9^{\text {th }}$ International Online Information Meeting, London 3-5 December 1990. Oxford: Learned Information, pp. 323-330.

Badenfelt, U., 2008. The selection of sharing ratios in target cost contracts. Engineering, Construction and Architectural Management, 15(1), pp. 54-65.

Basias, N. and Pollalis, Y., 2018. Quantitative and qualitative research in business and technology: Justifying a suitable research methodology. Review of Integrative Business and Economics Research, 7(1), pp. 91-105.

Bing, L., Akintoye, A., Edwards, P.J. and Hardcastle, C., 2005. The allocation of risk in PPP/PFI construction projects in the UK. International Journal of Project Management, 23(1), pp. 25-35.

Boukendour, S. and Bah, R., 2001. The guaranteed maximum price contracts as call option. Construction Management and Economics, 19(6), pp. 563-567.

Broome, J. and Perry, J., 2002. How practitioners set share fractions in target cost contracts. International Journal of Project Management, 20(1), pp. 59-66.

Chan, D.W., Chan, A.P., Lam, T I.P. and Chan, H.L., 2010a. Exploring the key risks and risk mitigation measures for guaranteed maximum price and target cost contracts in construction. Construction Law Journal, 26(5), pp. 364-378.

Chan, D.W., Chan, A.P., Lam, T.I.P. and Wong, J.M., 2010b. Empirical study of the risks and difficulties in implementing guaranteed maximum price and target cost contracts in construction. Journal of Construction Engineering and Management, 136(5), pp. 495-507.

Chan, D.W., Chan, A.P., Lam, P.T., Yeung, J.F. and Chan, J. H., 2011. Risk ranking and analysis in target cost contracts: Empirical evidence from the construction industry. International Journal of Project Management, 29(6), pp. 751-763. 
Chan, D.W., Chan, J.H. and Ma, T., 2014. Developing a fuzzy risk assessment model for guaranteed maximum price and target cost contracts in South Australia. Facilities, 32(11), pp. 624-646.

Chan, J.H., Chan, D.W., Chan, A.P. and Lam, P.T., 2012. Risk mitigation strategies for guaranteed maximum price and target cost contracts in construction. Journal of Facilities Management, 10(1), pp. $6-25$.

Chilumo, J., Odiembo, S., Zedekiah, A., Ruwa, A.H., Mwakwi, S., Kithome, O.M. and Kyalo, D. N., 2020. Risk management practices on performance of building construction projects. Journal of Entrepreneurship and Project Management, 4(6), pp. 38-57.

Davis Langdon and Seah Singapore, 2004. Guaranteed maximum price contracts. Executive summaries for the practitioner, 4(1), pp. 1-4.

Environment Transport and Works Bureau, 2005. Risk management for public works: risk management user manual. [Online] Available from: https:/www.devb.gov.hk/filemanager/technicalcirculars/ [Accessed 12 April 2021].

Eriksson, P.E., Lingegard, S., Borg, L. and Nystrom, J., 2017. Procurement of railway infrastructure projects - A European benchmarking study. Civil Engineering Journal, 3(4), pp. 199-213.

Fan, C.W.A. and Greenwood, D., 2004. Guaranteed maximum price for the project?. Surveyors Times, 13(3), pp. 20-21.

Hallowell, M.R. and Gambatese, J.A., 2010. Qualitative research: Application of the Delphi method to CEM research. Journal of Construction Engineering and Management, 136(1), pp. 99-107.

Hsu, C.C. and Sandford, B.A., 2007. The Delphi technique: Making sense of consensus. Practical Assessment, Research and Evaluation, 12(1), pp. 1-8.

Joseph, C.H.L., 2011. Developing a fuzzy risk assessment model for target cost and guaranteed maximum price contracts in the construction industry of Hong Kong. Thesis (PhD). The Hong Kong Polytechnic University.

Ma, T. and Beh, P.H.W., 2011. Guaranteed maximum price contracting - a qualitative study in South Australian construction industry. In International Conference on Construction and Real Estate Management, Brisbane, Australia 1 December 2010, pp. 1-12.

Nworie, J., 2011. Using the Delphi technique in educational technology research. TechTrends, 55(5), pp. 24-30.

Olawale, Y.A. and Sun, M., 2010. Cost and time control of construction projects: inhibiting factors and mitigating measures in practice. Construction Management and Economics, 28(5), pp. 509-526.

Osipova, E. and Eriksson, P.E., 2011. How procurement options influence risk management in construction projects. Construction Management and Economics, 29(11), pp. 1149-1158.

Oztas, A. and Okmen, O., 2004. Risk analysis in fixed-price design-build construction projects. Building and Environment, 39(2), pp. 229-237.

Rahman, M.M. and Kumaraswamy, M.M., 2005. Assembling integrated project teams for joint risk management. Construction Management and Economics, 23(4), pp. 365-375.

Rojas, E.M. and Kell, I., 2008. Comparative analysis of project delivery systems cost performance in Pacific Northwest public schools. Journal of Construction Engineering and Management, 134(6), pp. 387-397.

Rooshdi, R.R.R.M., Majid, M.Z.A., Sahamir, S. R. and Ismail, N.A A., 2018. Relative importance index of sustainable design and construction activities criteria for green highway. Chemical Engineering Transactions, 63, pp. 151-156.

Rotimi, J.O.B., Smith, L. and Ogunsemi, D.R., 2009. Managing the risks associated with scope changes in guaranteed maximum price (GMP) contracts. In Fourth Built Environment Conference (ASOCSA 2009), Lavington, Zambia, May 2009, pp. 1-9.

Wong, A.K., 2006. The application of computerized financial control system for the decision support of target cost contracts. Journal of Information Technology in Construction, 11(1), pp. 257-268.

Zimina, D., Ballard, G. and Pasquire, C., 2012. Target value design: Using collaboration and a lean approach to reduce construction cost. Construction Management and Economics, 30(5), pp. 383-398. 